Canadian

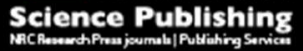

Botany

Botanique

\title{
Lophodermium resinosum sp. nov. from red pine (Pinus resinosa) in Eastern Canada
}

\begin{tabular}{|r|l|}
\hline Journal: & Botany \\
\hline Manuscript ID & cjb-2017-0012.R1 \\
\hline Danuscript Type: & Article \\
\hline Complete List of Authors: & $\begin{array}{l}\text { Tanney, Joey; Ottawa Research and Development Centre, Agriculture and } \\
\text { Agri-Food Canada, Biodiversity (Mycology \& Botany) } \\
\text { Seifert, Keith; Ottawa Research and Development Centre, Agriculture and } \\
\text { Agri-Food Canada, Biodiversity (Mycology \& Botany) }\end{array}$ \\
\hline $\begin{array}{r}\text { Please Select from this Special } \\
\text { Issues list if applicable: }\end{array}$ & N/A \\
\hline Keyword: & $\begin{array}{l}\text { cryptic species, Leotiomycetes, molecular systematics, Rhytismataceae, } \\
\text { Rhytismatales }\end{array}$ \\
\hline
\end{tabular}

SCHOLARONE $^{\mathrm{m}}$

Manuscripts 
Lophodermium resinosum sp. nov. from red pine (Pinus resinosa) in Eastern Canada

Joey B. Tanney ${ }^{\mathrm{a}}$

Keith A. Seifert ${ }^{b}$

Biodiversity (Mycology \& Botany), Ottawa Research and Development Centre, Agriculture and Agri-Food Canada, Ottawa, Ontario, K1A 0C6 Canada

a Joey.Tanney@agr.gc.ca

${ }^{\text {b } K e i t h . S e i f e r t @ a g r . g c . c a ~}$

Corresponding author:

\section{J.B. Tanney}

Biodiversity (Mycology \& Botany), Ottawa Research and Development Centre, Agriculture and Agri-Food Canada, Ottawa, Ontario, K1A 0C6 Canada.

Telephone: (613)-759-1820

Joey.Tanney@agr.gc.ca 


\begin{abstract}
A morphologically distinct Lophodermium species was collected from fallen secondary needles of Pinus resinosa over two consecutive years in Eastern Ontario; subsequent herbarium studies confirmed its presence in Nova Scotia, Quebec, and Maine. Symptomatic needles frequently exhibited red bands and completely subepidermal ascomata and conidiomata. Ascospore isolates from specimens were used to reconstruct phylogenies inferred from internal transcribed spacer rDNA and partial actin gene sequences. Both phylogenetic analyses delineated the specimens from other sequenced Lophodermium species. Phylogenetic evidence combined with morphological characters of ascomata and conidiomata supported the distinctiveness of this species, described here as Lophodermium resinosum sp. nov.
\end{abstract}

Keywords: cryptic species, Leotiomycetes, molecular systematics, Rhytismataceae, Rhytismatales 


\section{Introduction}

Lophodermium species (Rhytismataceae, Rhytismatales) are common foliar endophytes, saprotrophs, and pathogens of conifer trees. Molecular studies indicate the polyphyly of Lophodermium, thus morphological characters considered diagnostic for Lophodermium, notably elliptical ascomata opening by a single longitudinal slit, filiform ascospores surrounded by a gelatinous sheath, and leptostroma-like asexual states, are not synapomorphic (Lantz et al. 2011; Gao et al. 2013). Recent work also reveals the presence of species complexes and cryptic species in Lophodermium growing on Pinus foliage, including examples of novel species delimited among specimens formerly grouped together and misidentified as L. pinastri (Sokolski et al. 2004; Hou et al. 2009; Reignoux et al. 2009; Gao et al. 2013; Reignoux et al. 2014; Oono et al. 2015). Given (1) the recent description of novel cryptic Lophodermium species, (2) the unaccounted diversity of Rhytismataceae and possibility of narrow host preferences, and (3) the historical propensity of mycologists to identify North American specimens with names originally described from European type material, the delimitation and identity of Lophodermium species associated with conifer hosts endemic to North America should be re-examined. The identification of novel bioactive secondary metabolites from strains of Lophodermium and other Rhytismataceae species in eastern Canada gives impetus and relevance to this research (Sumarah et al. 2008; Sumarah et al. 2011; Sumarah et al. 2015).

In this study, specimens of a Lophodermium species were collected from fallen secondary needles of Pinus resinosa in late spring over two successive years in Eastern Canada. Reports of Lophodermium from Pinus resinosa are scarce, but include L. australe, L. nitens, L. pinastri, and L. seditiosum (Dearness 1926; Farr and Rossman 2016); detailed morphological study indicated the specimens we collected were distinct from these species and warranted further examination. Phylogenetic analyses using the internal transcribed spacer rDNA (ITS) marker and partial actin (ACT) gene sequences combined with morphological observations of the fresh collections and Lophodermium 
herbarium specimens provide evidence supporting the distinctiveness and consequent recognition of a novel Lophodermium species, described here as L. resinosum.

\section{Materials and methods}

Sampling and isolation

Field specimens were collected from fallen Pinus resinosa secondary needles in a mature $P$. resinosa plantation, a part of the Larose Forest established in 1928 in Clarence-Rockland, Ontario, Canada. Ascospore isolations were made on 2\% malt extract agar (MEA; 20 g Bacto malt extract, Difco Laboratories, Sparks, Maryland; 15 g agar, EMD Chemicals Inc., New Jersey; 1 L distilled water) or corn meal agar (CMA; Acumedia Manufacturers Inc., Lansing, MI). Monoascospore and polyascospore cultures were made by suspending mature ascomata from the lids of $6 \mathrm{~cm}$ Petri dishes using drops of sterile deionized water and allowing ascospores to eject downward onto the agar surface. Individual ascospores were transferred to $6 \mathrm{~cm}$ Petri dishes containing MEA using an electrolytically sharpened tungsten needle (Brady 1965). Ascospores were verified for germination and incubated at $16^{\circ} \mathrm{C}$ under 12:12 h light conditions. Dried specimens were accessioned in, and supplementary preserved specimens were obtained from, the Canadian National Mycological Herbarium (Ottawa, Canada; DAOM). Living cultures were deposited in the Canadian Collection of Fungal Cultures (Ottawa, Canada; DAOMC). Morphological observations

Sections of apothecia and conidiomata were cut by hand using a safety razor blade or with a freezing microtome and mounted in either water, $5 \% \mathrm{KOH}$, Lugol's solution with or without $5 \% \mathrm{KOH}$ pretreatment to test amyloid reactions (Baral 1987), or $85 \%$ lactic acid. Colony colours were described using the alphanumeric codes of Kornerup and Wanscher (1978). Morphological descriptions and measurements were made with living material. Microscopic measurements were taken from material mounted in deionized water and are presented as ranges calculated from the mean \pm standard deviation of each measured value with outliers in brackets. Observations were made using an Olympus BX50F4 
light microscope (Olympus, Tokyo, Japan) and an Olympus SZX12 stereomicroscope and images were captured with an InfinityX-32 camera (Lumenera Corp., Ottawa, Canada) using Infinity Analyze v6.5.2 (Lumenera Corp.) software. Photographic plates were assembled using Adobe Photoshop v5.5 (Adobe Systems, San Jose, California). Cardinal temperatures were assessed for two strains (DAOMC 251482 and DAOMC 251485) by incubating three-point inoculated $9 \mathrm{~cm}$ Petri dishes containing MEA at $5{ }^{\circ} \mathrm{C}$ intervals from $5-40^{\circ} \mathrm{C}$. Each treatment was conducted in triplicate and colony diameters were measured two and four wk after inoculation. Plates showing no growth were then incubated at $20^{\circ} \mathrm{C}$ to determine viability.

\section{DNA extraction and analyses}

Total genomic DNA was extracted from 12-wk-old cultures using the Ultraclean Microbial DNA Isolation Kit (Mo Bio Laboratories, Carlsbad, California) following the manufacturer's protocol. The primers ITS4 and ITS5 (White et al. 1990) were used to amplify and sequence the ITS region and ACT512F and ACT-783R were used to amplify and sequence part of the actin (ACT) gene (Carbone and Kohn 1999). Translation elongation factor- $1 \alpha(T E F 1 \alpha)$ gene was partially amplified and sequenced using EF1983 and EFgr (Rehner 2001) and partial LSU region was amplified using the primer pairs LROR and LR8 and sequenced using LROR, LR3R, LR5, and LR7 (Vilgalys and Hester 1990). DNA was amplified using the methods described in Nguyen et al. (2013). All loci were amplified using the following PCR profile: $95^{\circ} \mathrm{C}$ for $3 \mathrm{~min}$, then $35 \mathrm{cycles}$ at $95^{\circ} \mathrm{C}$ for $1 \mathrm{~min}, 56^{\circ} \mathrm{C}$ for $45 \mathrm{~s}$, and $72{ }^{\circ} \mathrm{C}$ for $1.5 \mathrm{~min}$, followed by a final extension at $72{ }^{\circ} \mathrm{C}$ for $10 \mathrm{~min}$.

For a herbarium specimen of Meloderma dezmazierii (DAOM 89807), DNA was extracted from fragments of symptomatic needles using the NucleoMag Trace kit (Macherey-Nagel, Düren, Germany) with an initial tissue grinding stage in liquid nitrogen using an Axygen polypropylene pestle (PES-15-B-SI, Union City, California), with the same PCR protocol as above including the addition of $0.5 \mu \mathrm{L}$ of $20 \mathrm{mg} / \mathrm{ml}$ bovine serum albumin (BSA; Thermo Fisher Scientific, Waltham, MA) to the PCR reaction. All PCR 
products were verified by agarose gel electrophoresis and sequenced with Big Dye Terminator (Applied Biosystems, Foster City, California).

Sequence contigs were assembled, trimmed, and manually checked using Geneious v8.1.5 (Biomatters, Auckland, New Zealand) and each individual gene dataset aligned by the MAFFT v7.017 algorithm within Geneious (Katoh et al. 2002). The resulting alignments were trimmed and manually checked within Geneious.

The ITS dataset included 64 sequences and 494 positions and the ACT dataset consisted of 42 sequences and 297 positions. TEF1 $\alpha$ was excluded from phylogenetic analysis because of a lack of representative Rhytismatales sequences available. Bayesian analyses were performed for each individual gene dataset using MrBayes v3.2 (Ronquist et al. 2012) and the most suitable sequence evolution models selected for each gene based on the optimal Akaike information criterion scores in MrModeltest v2.2.6 (Nylander 2004): GTR+I+G for ITS and GTR+G for ACT. Lophodermium piceae (FR837918) was selected as outgroup for the ITS analysis because previous studies place it at the base of Rhytismatales (Ortiz-García et al. 2003; Lantz et al. 2011). Hymenoscyphus epiphyllus (Helotiaceae, Helotiales; FJ005192) was outgroup for the ACT analysis based on previous analyses (Koukol et al. 2015; Li et al. 2016). For each alignment, three independent Metropolis-coupled Markov chain Monte Carlo (MCMCMC) runs were simultaneously performed with four chains (three heated and one cold) with sampling every 500 generations until the standard deviation of split frequencies reached a value $<0.01$. The first $25 \%$ of trees were discarded as burn-in and the remaining trees were kept and combined into one $50 \%$ majority-rule consensus tree. Convergence was assessed from the three independent runs using Tracer v1.6 (Rambaut et al. 2014). Consensus trees were imported into FigTree v1.4.2 (Rambaut 2014) and exported as SVG vector graphics for assembly in Adobe Illustrator v10 (Adobe Systems). All novel sequences used in this study were accessioned in GenBank (Table 1) and taxonomic novelties and associated metadata were deposited in MycoBank (www.MycoBank.org). 


\section{Results}

The ITS and ACT phylogenies show branches with low-moderate support overall and many polytomous clades, which is expected given the sampling gaps in sequences available for Lophodermium and related genera (Figs. 1-2). The lack of available ACT sequences for Lophodermium and other Rhytismataceae species did not allow for a combined analysis, therefore asymmetrical datasets were used. The new species Lophodermium resinosum formed a well-supported distinct clade in both the ITS and ACT phylogenetic analyses. The ITS phylogeny placed L. resinosum sister to L. molitoris (posterior probability $(\mathrm{PP})=0.96)$ while the $A C T$ phylogeny, lacking available $L$. molitoris sequences, placed $L$. resinosum sister to Lophodermium kumaunicum $(\mathrm{PP}=0.99)$.

A GenBank BLAST of Lophodermium resinosum ITS sequences revealed three closely related matches with unidentified Picea glauca endophytes: DQ068338, DQ068340, (identities = 464/465 (99\%), gaps $=0 / 465)$ and DQ068339 (identities $=463 / 465(99 \%)$, gaps $=0 / 465)$. The next closest related sequences in GenBank included unidentified endophytes isolated from Pinus taeda (KM519348: identities $=462 / 478(97 \%)$, gaps = 3/478 (0\%) and Pinus monticola (HQ535910: 471/492 (96\%), 4/492(0\%); HQ535923, HQ535897: 470/492 (96\%), 2/492(0\%).

A study of Lophodermium pinastri and L. seditiosum DAOM herbarium specimens from Pinus resinosa confirmed the presence of Lophodermium resinosum from additional localities, listed below. Lophodermium resinosum was represented in the DAOM collection by 11 specimens identified as $L$. pinastri and one specimen identified as L. seditiosum (DAOM 198724).

\section{Taxonomy}

Lophodermium resinosum J.B. Tanney \& Seifert, sp. nov.

Fig. 3

MycoBank MB819741. 
Etymology: Named to correspond with the host epithet, Pinus resinosa.

Diagnosis: Morphologically similar to Lophodermium seditiosum, but with smaller ascomata, covering stroma that extends as far as the basal wall, inostiolate conidiomata, and an ITS sequence distinct from L. seditiosum ex-type (ATCC 28345). ITS (KY485127), ACT (KY485130), and LSU (KY485133) sequences are distinct from all available Lophodermium and Rhytismataceae sequences.

Typus: Canada, Ontario, Clarence-Rockland, Larose Forest, ex fallen secondary needles of Pinus resinosa, coll. May 31, 2015, J.B. Tanney \& B. Tanney (holotype DAOM 745753; culture ex-type DAOMC 251482).

ITS barcode: KY485127 (alternative markers: $A C T=\mathrm{KY} 485130 ;$ TEF1 $\alpha=\mathrm{KY702582}$ LSU = KY485133).

Colony description based on DAOMC 251482 at $20{ }^{\circ} \mathrm{C}$ after $14 \mathrm{~d}$ in dark: $12-15 \mathrm{~mm}$ diam; planar with sparse to moderate aerial hyphae; margin diffuse and hyaline; surface hyaline to pale orange to greyish orange (5A3-5B4); reverse orange grey to greyish orange (5B2-5B3). Exudates and soluble pigments absent. Conidiomata sometimes forming within 4 wk, occurring singly, scattered, on agar surface or submerged, morphologically different from conidiomata on host, up to $1 \mathrm{~mm}$ diam, dark brown to black, globose, with conidia dimensions same as those from host. Mycelium consisting of hyaline to pale brown, smooth, septate, branched, hyphae 1.5-4(-6) $\mu \mathrm{m}$ diam.

Ascomata mostly on adaxial and less frequently abaxial surfaces of needles, subepidermal, (500600-950(-1100) × 300-500(-600) $\mu \mathrm{m}$, scattered, occasionally coalescing, elliptical, shiny, black, margin paler, opening by a longitudinal fissure with grey to black lips. Lip cells ovoid to cylindrical-clavate, hyaline to subhyaline, up to $17 \mu \mathrm{m}$ long, arranged more or less radially, often invested in mucus, not always evident. Covering stroma dark brown, 18-25 $\mu \mathrm{m}$ thick towards edges, $20-55 \mu \mathrm{m}$ thick towards lips, covered by host epidermis, extending to basal stroma, consisting of textura angularis to textura epidermoidea, cells 3-8 $\mu \mathrm{m}$ diam, thick-walled (ca. $1 \mu \mathrm{m}$ thick). Basal stroma dark brown, concave, 
occurring within host epidermal cells, poorly developed, consisting of textura angularis to textura epidermoidea, cells $2.5-4 \mu \mathrm{m}$ diam, thin- to thick-walled. Subhymenium 14-28 $\mu \mathrm{m}$ thick, hyaline, consisting of textura angularis and textura intricata. Paraphyses septate, filiform, unbranched, hyaline, smooth-walled, covered in 1-2 $\mu \mathrm{m}$ thick gelatinous sheath that frequently appears discontinuous and granular with maturity, 4-5.5 $\mu \mathrm{m}$ thick at base, tapering to $2.5 \mu \mathrm{m}$, apices rounded to irregularly subclavate, as long as mature asci, connected at base by hyphal bridges. Asci (120-)125-150(-165) × 11-14(-16) $\mu \mathrm{m}$, cylindrical to clavate-cylindrical, apex rounded to subpapillate, more or less sessile, inamyloid, 8-spored, thin-walled, maturing sequentially. Ascospores (83.5-)104.5-125.5(-133.5) × 22.5(-3) $\mu \mathrm{m}$ (length: $\mathrm{n}=54, \overline{\mathrm{x}}=115 \mu \mathrm{m}, \mathrm{SD}=10.5 \mu \mathrm{m}, \mathrm{SE}=1.43 \mu \mathrm{m}, 95 \% \mathrm{Cl}=2.79$; width: $\mathrm{n}=54 \mu \mathrm{m}, \overline{\mathrm{x}}=$ $2.5 \mu \mathrm{m}, \mathrm{SD}=0.2 \mu \mathrm{m}, \mathrm{SE}=0.03 \mu \mathrm{m}, 95 \% \mathrm{Cl}=0.05)$, filiform, ends rounded, tapered towards base, hyaline, contents sometimes appearing granular, smooth-walled, covered by a well-developed, more or less uniform, 1.5-2(-2.5) $\mu \mathrm{m}$ thick gelatinous sheath that appears denser and bulbous at both ends, sheath (3-)4-5(-5.5) $\mu \mathrm{m}$ thick at apex and (2-)2.5-4(-4.5) $\mu \mathrm{m}$ thick at base, arranged parallel or sometimes helically coiled.

Conidiomata mostly on adaxial and less frequently abaxial surfaces of needles, subepidermal, co-occurring with ascomata, scattered to crowded or coalescing, appearing as flat to raised, irregularly oval to elliptical, blister-like swellings on tissue, dull to shiny, concolorous or paler than surrounding host tissue, becoming darker with age, margin often brown or dark brown, 300-500 (-800) $\times(100-) 150-300$ $\mu \mathrm{m}$, opening by lateral fissures. Subconidiogenous layer 7-14 $\mu \mathrm{m}$ thick, hyaline to subhyaline, consisting of textura globulosa, thin-walled cells. Conidiogenous cells $(9.5-) 10-16(-19) \times 2-3 \mu \mathrm{m}$, cylindrical to broadly ampulliform, tapering towards apex, sometimes swollen at base or above midcentre, hyaline, indeterminate, discrete, extending sympodially. Conidia (3.5-)4.5-6(-8) $\times 1-1.5 \mu \mathrm{m}$ (length: $\mathrm{n}=100, \overline{\mathrm{x}}=$ $5.25 \mu \mathrm{m}, \mathrm{SD}=0.1 \mu \mathrm{m}, \mathrm{SE}=0.08 \mu \mathrm{m}, 95 \% \mathrm{Cl}=0.16 ;$ width: $\mathrm{n}=100, \overline{\mathrm{x}}=1.45 \mu \mathrm{m}, \mathrm{SD}=0.12 \mu \mathrm{m}, \mathrm{SE}=0.01$ 
$\mu \mathrm{m}, 95 \% \mathrm{Cl}=0.02$ ), oblong, ends rounded and sometimes broadly tapered at base, straight, hyaline, smooth-walled, exuded in slimy pale to buff mass from irregular rupture in covering host epidermis.

Cardinal temperatures: Range $5-30^{\circ} \mathrm{C}$, optimum $25^{\circ} \mathrm{C}$, minimum $5^{\circ} \mathrm{C}$, maximum slightly $>30^{\circ} \mathrm{C}$. Habitat: On fallen secondary needles of Pinus resinosa.

Distribution: Canada: Ontario, Quebec, Nova Scotia; USA: Maine.

Notes: Infected needles rarely exhibiting black zone lines, instead frequently having red bands 100-400 $\mu \mathrm{m}$ wide, and ascomata and conidiomata usually mature May-June. Lophodermium resinosum is distinguished from the morphologically similar L. seditiosum by its smaller ascomata (vs. 800-1600 $\mu \mathrm{m}$ sensu Minter 1981), covering stroma extending as far as the basal wall, and inostiolate conidiomata. Other species that form completely subepidermal ascomata differ from L. resinosum by their lack of lips and splitting along a line of stromata (L. baculiferum; Minter 1980), conidia >15 $\mu \mathrm{m}$ long (L. ravenelii; Minter 1981), or smaller ascospores, e.g.: L. pini-pumilae $(87-91 \times 2 \mu \mathrm{m}$; Minter 1981) and L. orientale (55-85 × $2 \mu \mathrm{m}$; Minter 1981). Lophodermium resinosum differs morphologically from L. staleyi by its larger ascospores (vs. 70-115 × 9-12 $\mu \mathrm{m}$; Minter 1981) and smaller conidia (vs. 8-12 × $1 \mu \mathrm{m}$; Minter 1981). Ascomata of $L$. resinosum are readily distinguished from those of $L$. australe, $L$. conigenum, $L$. pinastri, and L. pini-excelsae by being totally subepidermal. Lophodermium resinosum is morphologically distinct from L. molitoris, the closest relative in the ITS phylogeny, most notably by its subepidermal vs. subcuticular ascomata (Minter 1980). It differs morphologically from L. kumaunicum, the closest relative in the ACT phylogeny, by its longer ascospores (vs. 60-90 × 1-1.5 $\mu \mathrm{m}$; Minter and Sharma 1982) and subepidermal vs. subcuticular or partly subepidermal ascomata (Fig. 3).

Other specimens examined (all ex Pinus resinosa needles): CANADA: Nova Scotia: Pictou Co., Blue Mountain, 31 Aug. 1933, I.H. Crowell (DAOM 24828); Ontario: Prescott and Russell Co., ClarenceRockland, Larose Forest, 8 Jun. 2015, J.B. Tanney \& B. Tanney (DAOM 745754, DAOMC 251483, DAOMC 251844, DAOMC 251485, DAOMC 251486, DAOMC 251514, DAOMC 251515); Carleton Co., Buckham 
Bay, 17 Sep. 1960, G.D. Darker (DAOM 74359); Lake Temagami, Gull Lake Portage, 26 Jun. 1929, G.E. Thompson (DAOM 86496); Lake Temagami, Spawning Bay Portage, 26 Jun. 1932, R.F. Cain, (DAOM 86494); Lake Temagami, Bear Island, 19 Jun. 1932, R.F. Cain, (DAOM 86498); Lake Temagami, Bear Island, 3 Jul. 1929, G.E. Thompson (DAOM 86497); Petawawa, Orange Road, 4 Jul. 1940, C.G. Riley (DAOM 24042); Petawawa, Orange Road Plantation, 28 Jun. 1940, A.J. Skolko (DAOM 6103); South Plantagenet Township, 9 Jun. 1988, A. Keizer (DAOM 198724); Quebec: Rimouski Co., Bic sur Mer, 13 Sep 1961, G.D. Darker (DAOM 84530); île Perrot, 20 May 1939, I.H. Crowell (DAOM 218306); U.S.A.: Maine: Eustis, needles of cut trees, 29 Jul 1935, J.R. Hansbrough (DAOM 48675).

\section{Discussion}

Lophodermium resinosum forms abundant ascomata and conidiomata on fallen secondary needles of Pinus resinosa across northeastern North America. The ecology of L. resinosum is currently unknown, for example whether it exhibits a prolonged endophytic infection preceding a saprotrophic phase initiated by foliage senescence and abscission, or if it is an opportunistic pathogen. Lophodermium resinosum is only known from fallen secondary needles; the presence of $L$. resinosum on attached needles from cut trees (DAOM 48675) suggests the fungus exists endophytically and sporulates following needle death.

The distinctiveness and novelty of $L$. resinosum was overlooked by previous workers examining Lophodermium on Pinus resinosa, probably because of the broad application of the name L. pinastri to specimens bearing superficially-similar ascomata that actually represent distinct species (Sokolski et al. 2004). For example, our ITS phylogeny (Fig. 1) shows the names L. pinastri and L. conigenum are applied to sequences forming phylogenetically distinct clades, probably representing species that are undescribed or named-but-unsequenced, such as L. staleyi (Reignoux et al. 2014). In general, the historical misapplication of names to Rhytismatales specimens resulted in erroneous species concepts 
that are too broad and potentially conceal diagnostic or distinctive biological and ecological traits. North American Rhytismatales biodiversity is undersampled and underestimated, especially given the frequent application of European species names to North American specimens based on superficial morphological similarities. Several studies reveal the presence of novel cryptic or overlooked species misidentified as European species in North America, such as Rhytisma americanum (Hudler et al. 1998), Lophodermium macci (Sokolski et al. 2004), and L. "piceae" (Stefani and Bérubé 2006a), while Chinese species of Lophodermium and Tryblidiopsis have also been distinguished from their European look-alikes (Gao et al. 2013; Wang et al. 2014). While Oono et al. (2014) suggested that all Pinus species can potentially host most Lophodermium species, this is unlikely given the polyphyly of Lophodermium and apparent narrow host preferences observed in other Rhytismataceae species, for example Lirula macrospora, Lophodermium piceae s.s., and Tryblidiopsis pinastri restricted to Picea abies (Lantz et al. 2011; Tanney unpub data), Isthmiella faullii restricted to Abies balsamea (Darker 1932), Lophophacidium dooksii restricted to Pinus strobus (Corlett and Shoemaker 1984; Laflamme et al. 2015), and Rhytisma salicinum and Cryptomyces maximus restricted to Salix (Lantz et al. 2011). However, closely-related ITS sequences of Lophodermium species derived from disjunct locales and more distantly related Pinus hosts indicates that some species are not restricted to specific Pinus species or subsections (Ortiz-García et al. 2003; Johnston et al. 2003; Oono et al. 2014). Further sampling of Lophodermium and other Rhytismatales from endemic North American hosts is therefore encouraged to elucidate biodiversity, host ranges, and provide evidence of host-tracking coevolution and speciation.

Previous observations of Lophodermium on Pinus resinosa name Lophodermium pinastri and $L$. seditiosum as causal agents of needle cast causing mortality or severe damage to Pinus resinosa and $P$. sylvestris in North American nurseries and plantations during the 1960-1980s (Nicholls and Skilling 1970; Ostry and Nicholls 1989). Skilling and Nicholls (1975) described what they interpreted as two Lophodermium pinastri biotypes isolated from symptomatic Pinus resinosa and P. sylvestris trees in 
Christmas tree plantations: one type was pathogenic, isolated primarily from 1- and 2-year-old needles and produced brown mycelia in culture, while the other type was isolated from older needles and produced white mycelia in culture. Other workers have noted differences in pathogenicity, cultural and apothecial morphology, and ecology of Lophodermium pinastri "types" on Pinus sylvestris, which in consideration of recent molecular work, provides compelling evidence for the existence of undescribed species (Darker 1932; Millar and Watson 1971; Reignoux et al. 2014; Koukol et al. 2015). Wilson et al. (1994) identified 27 distinct genotypes of Lophodermium pinastri isolated as Pinus resinosa endophytes in Eastern Canada, but again their identities cannot be confirmed without morphological evidence or available sequences. Connecting precise taxonomic names to such records would allow valuable field observations (e.g.: pathogenicity reports) to be reinterpreted.

The epitypification of species using material from original host species and type locales is crucial to provide benchmarks for species and generic concepts within Rhytismatales, an order consisting of numerous large polyphyletic families that must be resolved (Lantz et al. 2011). New collections and epitypification efforts should focus on taxonomically important species, such as Lophodermium arundinaceum, L. piceae, and L. pinastri, and unsequenced type species of genera such as Isthmiella abietis and Lirula nervisequa. Lophodermium is polyphyletic and the type species, L. arundinaceum, occupies a clade consisting primarily of Poaceae associates (Lantz et al. 2011). This is an unfortunate lectotype species, because in the pursuit of monophyletic taxa, Lophodermium is likely to be eventually restricted to this clade of largely graminicolous species, resulting in the taxonomic upheaval of more frequently reported species such as important conifer associates. Additional sampling and phylogenetic study is required, especially for type species and genera unrepresented by sequence data, before making drastic taxonomic and nomenclatural changes to these genera.

Unfortunately, asymmetrical datasets of available ITS and ACT sequences resulted in discrepancies in our phylogeny. For example the ITS tree places L. resinosum sister to L. molitoris $(\mathrm{PP}=$ 
0.96) and the $A C T$ phylogeny places L. resinosum sister to L. kumaunicum ( $P P=0.99)$. To reduce such difficulties caused by missing data, cultures of unrepresented and novel species should be generated whenever possible and deposited in publicly available collections and sequences of the ITS barcode, LSU, and protein-coding phylogenetic markers such as ACT and TEF1 $\alpha$ made available in NCBI GenBank. In consideration of the taxonomic issues surrounding Rhytismatales, we discourage the description of novel Rhytismatales species without representative sequences of at least the ITS barcode.

Rhytismatales species may be readily distinguished using the ITS barcode and other secondary barcodes. Lophodermium resinosum ITS sequences showed 99\% similarity to three sequences in GenBank (DQ068338, DQ068340, and DQ068339) originating from endophyte cultures from surface sterilized Picea glauca needles sampled from separate trees within a plot in eastern Canada (Stefani and Bérubé 2006b). Lophodermium resinosum has not been recovered in other Picea endophyte studies and Stefani and Bérubé (2006b) described the sampling site as a Picea glauca plantation surrounded by a mixture of mature Pinus resinosa and $P$. strobus. It is unexpected that Lophodermium resinosum would occur on both Pinus resinosa and Picea glauca and plausible that L. resinosum ascospores adhering to Picea glauca needles survived the surface sterilization process, resulting in its detection as an apparent P. glauca endophyte. However, the ability of Lophodermium resinosum to endophytically infect Picea glauca, while doubtful, cannot be ruled out.

In general, Rhytismatales sequence data are scant, especially for non-rDNA loci; therefore amassing available $A C T$ and other gene sequences (e.g.: TEF1 $\alpha$ ) by the relatively small community focussing on Rhytismatales is imperative to provide data for phylogeny-based taxonomic treatments. Several studies adopted ACT as a secondary phylogenetic marker for Lophodermium (e.g.: Oono et al. 2014; Reignoux et al. 2014; Koukol et al. 2015; Li et al. 2016). Species resolution and phylogenetic reconstruction using ACT appears satisfactory; for example, Reignoux et al. (2014) presented three Lophodermium pinastri clades that were congruent in both ITS and ACT phylogenies, although tree 
topologies differed (e.g.: L. pinastri clades were polytomous in ACT phylogeny). ACT is readily amplified in Lophodermium species and sequences are typically $<300 \mathrm{bp}$, making it a potentially useful secondary barcode despite its short length. It is also appealing for sequencing Rhytismatales herbarium specimens, where DNA is often fragmented or degraded, especially if it might be possible to develop Rhytismatalesspecific ACT primers. Stielow et al. (2015) reported an $84 \%$ amplification success for $A C T$ in a diverse sampling of Ascomycota and Basidiomycota samples, but different primer pairs were tested and no universal performing set was found.

At the time of writing, Rhytismatales species are poorly represented by TEF1 $\alpha$ sequences in GenBank; therefore species identification and phylogenetic analysis using TEF1 $\alpha$ is currently infeasible. Stielow et al. (2015) identified TEF1 $\alpha$ as the most promising universal secondary barcode candidate and, given its wide usage as a phylogenetic marker, TEF1 $\alpha$ should be considered in future Rhytismatales phylogenetic studies.

Pinus resinosa or red pine is an economically and ecologically important tree species in northeast North America and represents the only extant subsection Pinus species native to the continent. Despite its occurrence across a wide geographic range, phenotypic and genetic variation in Pinus resinosa is very low, probably resulting from a population bottleneck during the last glaciation event (Fowler and Morris 1977; Boys et al. 2005; Walter and Epperson 2005). Ascomycota records from Pinus resinosa are relatively sparse compared to other commercial North American conifers (Farr and Rossman 2016); the unique evolutionary history of $P$. resinosa should encourage sampling from this host. For example, did its expansion from smaller refugia populations also result in a biodiversity bottleneck for symbionts, or are many Pinus resinosa symbionts shared with other co-occurring conifer hosts?

The detection of a novel Lophodermium species on an endemic North American host with a poorly characterized microbiota is expected given the recent descriptions of novel Lophodermium and 
other Rhytismataceae species worldwide (e.g.: Wang et al. 2014; Koukol et al. 2015; Masumoto et al. 2015; Zhang et al. 2015). Furthering our understanding of the biodiversity and taxonomy of Rhytismatales species will reveal insight into the coevolution of these fungi and their hosts, provide reference sequences facilitating the identification of sequences from endophyte and other ecological surveys, and potentially lead to the identification of novel bioactive secondary metabolites. The detection and identification of the novel species Lophodermium resinosum from Pinus resinosa should therefore stimulate further taxonomic work on fungi associated with native plant hosts in Canada.

\section{Acknowledgements}

This study was supported by the Natural Sciences and Engineering Research Council of Canada PGSD2459312-2014 to J.B. Tanney and the NSERC CRDPJ 421782-11 to JD Miller. We are grateful to the Microbiology Molecular Technologies Laboratory (MMTL) group of ORDC-AAFC, Ottawa, for processing DNA sequencing and Quinn Eggertson for advice on sequencing herbarium specimens. 


\section{References}

Baral, H.O. 1987. Lugol's solution/IKI versus Melzer's reagent: hemiamyloidity, a universal feature of the ascus wall. Mycotaxon, 29: 399-450.

Boys, J., Cherry, M., and Dayanandan, S. 2005. Microsatellite analysis reveals genetically distinct populations of red pine (Pinus resinosa, Pinaceae). Am. J. Bot., 92(5): 833-841.

Brady, J. 1965. A simple technique for making very fine, durable dissecting needles by sharpening tungsten wire electrolytically. Bulletin of the World Health Organization, 32(1): 143.

Carbone, I., and Kohn, L.M. 1999. A method for designing primer sets for speciation studies in filamentous ascomycetes. Mycologia, 91(3): 553-556.

Corlett, M., and Shoemaker, R.A. 1984. Lophophacidium dooksii n. sp., a phacidiaceous fungus on needles of white pine. Can. J. Bot., 62(9): 1836-1840.

Darker, G.D. 1932. The Hypodermataceae of Conifers. Contrib. Arnold Arboretum, 1:1-131.

Dearness, J. 1926. New and Noteworthy Fungi: IV. Mycologia, 18(5): 236-255.

Farr, D., and Rossman, A. 2016. Fungal Databases, Systematic Mycology and Microbiology Laboratory, ARS, USDA [online]. Available from http://nt.ars-grin.gov/fungaldatabases/ [accessed 2 December 2016]. 
Fowler, D., and Morris, R. 1977. Genetic diversity in red pine: evidence for low genic heterozygosity. Can. J. Forest. Res., 7(2): 343-347.

Gao, X.-M., Lin, Y.-R., Huang, H.-Y., and Hou, C.-L. 2013. A new species of Lophodermium associated with the needle cast of Cathay silver fir. Mycol. Prog., 12(1): 141-149.

Hou, C.-L., Li, L., and Piepenbring, M. 2009. Lophodermium pini-mugonis sp. nov. on needles of Pinus mugo from the Alps based on morphological and molecular data. Mycol. Prog., 8(1): 29-33.

Hudler, G.W., Jensen-Tracy, S., and Banik, M.T. 1998. Rhytisma americanum sp. nov.: a previously undescribed species of Rhytisma on maples (Acer spp.). Mycotaxon, 68: 405-416.

Johnston, P., Park, D., Dick, M., Ortiz-García, S., and Gernandt, D. 2003. Identifying pine-inhabiting Lophodermium species using PCR-RFLP. New Zealand J. Forestry Sci., 33(1): 10-24.

Katoh, K., Misawa, K., Kuma, K.i., and Miyata, T. 2002. MAFFT: a novel method for rapid multiple sequence alignment based on fast Fourier transform. Nucleic Acids Res., 30(14): 3059-3066.

Kornerup, A., and Wanscher, J.H. 1978. Methuen handbook of colour. 3rd ed. Eyre Methuen, London, United Kingdom.

Koukol, O., Pusz, W., and Minter, D. 2015. A new species of Lophodermium on needles of mountain pine (Pinus mugo) from the Giant Mountains in Poland. Mycol. Prog., 14(5): 1-13. 
Laflamme, G., Broders, K., Côté, C., Munck, I., Iriarte, G., and Innes, L. 2015. Priority of Lophophacidium over Canavirgella: taxonomic status of Lophophacidium dooksii and Canavirgella banfieldii, causal agents of a white pine needle disease. Mycologia, 107(4): 745-753.

Lantz, H., Johnston, P., Park, D., and Minter, D.W. 2011. Molecular phylogeny reveals a core clade of Rhytismatales. Mycologia, 103(1): 57-74.

Li, Z.-J., Taylor, J., and Hou, C.-L. 2016. An unusual Lophodermium species on needles of Pinus taiwanensis from China. Mycol. Prog., 15(12): 1229-1237.

Masumoto, S., Tojo, M., Uchida, M., and Imura, S. 2015. Morphological and molecular characterization of Rhytisma filamentosum sp. nov. from Nagano Prefecture, Japan. Mycol. Prog., 14(6): 1-6.

Millar, C., and Watson, A.R. 1971. Two biotypes of Lophodermium pinastri in Scotland. Eur. J. For. Pathol., 1(2): 87-93.

Minter, D.W. 1980. Leptostroma on pine needles. Botany, 58(8): 906-917.

Minter, D.W. 1981. Lophodermium on pines. Mycol. Pap., 147: 1-54.

Minter, D.W. and Sharma, M.P. 1982. Three species of Lophodermium from the Himalayas. Mycologia, 74(5):702-711.

Nguyen, H.D., Nickerson, N.L., and Seifert, K.A. 2013. Basidioascus and Geminibasidium: a new lineage of heat-resistant and xerotolerant basidiomycetes. Mycologia, 105(5): 1231-1250. 
Nicholls, T.H., and Skilling, D.D. 1970. Lophodermium pinastri outbreak in lake states forest nurseries. Plant Dis. Rep., 54(9): 731-733.

Nylander, J. 2004. MrModeltest 2.2. Program distributed by the author., Evolutionary Biology Centre, Uppsala University, Uppsala.

Oono, R., Lefèvre, E., Simha, A., and Lutzoni, F. 2015. A comparison of the community diversity of foliar fungal endophytes between seedling and adult loblolly pines (Pinus taeda). Fungal Biol., 119(10): 917928.

Oono, R., Lutzoni, F., Arnold, A.E., Kaye, L., U’Ren, J.M., May, G., and Carbone, I. 2014. Genetic variation in horizontally transmitted fungal endophytes of pine needles reveals population structure in cryptic species. Am. J. Bot., 101(8): 1362-1374.

Ortiz-García, S., Gernandt, D.S., Stone, J.K., Johnston, P.R., Chapela, I.H., Salas-Lizana, R., and AlvarezBuylla, E.R. 2003. Phylogenetics of Lophodermium from pine. Mycologia, 95(5): 846-859.

Ostry, M.E., and Nicholls, T.H. 1989. Effect of Lophodermium seditiosum on growth of pine nursery seedlings in Wisconsin. Plant Dis., 73: 798-800.

Rambaut, A. 2014. FigTree v1. 4.2. Edinburgh: University of Edinburgh. 
Rambaut, A., Suchard, M., Xie, D., and Drummond, A. 2014. Tracer ver. 1.6. Available from http://beast.bio.ed.ac.uk/Tracer.

Rehner SA, 2001. EF1-alpha primers. USDA, ARS, PSI Insect Biocontrol Laboratory. Available from http://www.aftol.org/pdfs/EF1primer.pdf

Reignoux, S.N., Aitken, E.A.E., Green, S., and Ennos, R.A. 2009. Two new species of Lophodermium colonise Scots Pines needles in Scotland. Proceedings of the conference IUFRO working party 7.02.02, ISSN: 1302-7082, 15-23.

Reignoux, S.N., Green, S., and Ennos, R.A. 2014. Molecular identification and relative abundance of cryptic Lophodermium species in natural populations of Scots pine, Pinus sylvestris L. Fungal Biol., 118(9): 835-845.

Ronquist, F., Teslenko, M., van der Mark, P., Ayres, D.L., Darling, A., Höhna, S., Larget, B., Liu, L., Suchard, M.A., and Huelsenbeck, J.P. 2012. MrBayes 3.2: Efficient Bayesian phylogenetic inference and model choice across a large model space. Syst. Biol., 61(3): 539-542. doi: 10.1093/sysbio/sys029.

Skilling, D., and Nicholls, T. 1975. The development of Lophodermium pinastri in conifer nurseries and plantations in North America. Eur. J. For. Pathol., 5(4): 193-197.

Sokolski, S., Piché, Y., and Bérubé, J.A. 2004. Lophodermium macci sp. nov., a new species on senesced foliage of five-needle pines. Mycologia, 96(6): 1261-1267. 
Stefani, F., and Bérubé, J. 2006a. Biodiversity of foliar fungal endophytes in white spruce (Picea glauca) from southern Québec. Botany, 84(5): 777-790.

Stefani, F., and Bérubé, J. 2006b. Evaluation of foliar fungal endophyte incidence in field-grown transgenic Bt white spruce trees. Botany, 84(10): 1573-1580.

Stielow, J., Lévesque, C., Seifert, K., Meyer, W., Irinyi, L., Smits, D., Renfurm, R., Verkley, G., Groenewald, M., and Chaduli, D. 2015. One fungus, which genes? Development and assessment of universal primers for potential secondary fungal DNA barcodes. Persoonia, 35(1): 242-263.

Sumarah, M.W., Kesting, J.R., Sørensen, D., and Miller, J.D. 2011. Antifungal metabolites from fungal endophytes of Pinus strobus. Phytochemistry, 72(14): 1833-1837.

Sumarah, M.W., Puniani, E., Blackwell, B.A., and Miller, J.D. 2008. Characterization of polyketide metabolites from foliar endophytes of Picea glauca. J. Nat. Prod., 71(8): 1393-1398.

Sumarah, M.W., Walker, A.K., Seifert, K.A., Todorov, A., and Miller, J.D. 2015. Screening of fungal endophytes isolated from eastern white pine needles. In The Formation, Structure and Activity of Phytochemicals. Edited by R. Jetter. Springer International Publishing. pp. 195-206.

Vilgalys, R., and Hester, M. 1990. Rapid genetic identification and mapping of enzymatically amplified ribosomal DNA from several Cryptococcus species. J. Bacteriol., 172(8): 4238-4246. 
Walter, R., and Epperson, B.K. 2005. Geographic pattern of genetic diversity in Pinus resinosa: contact zone between descendants of glacial refugia. Am. J. Bot., 92(1): 92-100.

Wang, S., Cannon, P., Li, Z.-J., and Hou, C.-L. 2014. Multigene phylogenetic analysis detects cryptic species of Tryblidiopsis in China. Mycologia, 106(1): 95-104.

White, T., Bruns, T., Lee, S., and Taylor, J. 1990. Amplification and direct sequencing of fungal ribosomal RNA genes for phylogenetics. In PCR Protocols: A Guide to Methods and Applications. Edited by M. Innis and D. Gelfand and J. Sninsky and T. White. Academic Press, Inc., New York. pp. 315-322.

Wilson, R., Wheatcroft, R., Miller, J.D., and Whitney, N.J. 1994. Genetic diversity among natural populations of endophytic Lophodermium pinastri from Pinus resinosa. Mycol. Res., 98(7): 740-744.

Zhang, T.-T., Tong, X., Lin, Y.-R., and Hou, C.-L. 2015. A new species and a new combination of Terriera based on morphological and molecular data. Mycol. Prog., 14(8): 1-6. 
Table 1. Isolates used in phylogenetic analyses in this study; new sequences generated in this study are in bold.

\begin{tabular}{|c|c|c|c|c|}
\hline \multirow[t]{2}{*}{ Species } & \multirow[t]{2}{*}{ Strain/specimen identifier } & \multicolumn{3}{|c|}{ GenBank accession no. } \\
\hline & & ITS & $A C T$ & LSU \\
\hline Elytroderma deformans & CBS 181.68 & AF203469 & - & - \\
\hline Hymenoscyphus epiphyllus & HB7054 & - & FJ005192 & - \\
\hline Hypoderma junipericola & R104a & GU138754 & - & - \\
\hline Leptostroma decipiens & ja2n4t5 & AY100654 & - & - \\
\hline Leptostroma decipiens & $\mathrm{ma} 4 \mathrm{n} 7 \mathrm{~m} 1$ & AY100653 & - & - \\
\hline Lophodermium australe & $2 \mathrm{~V} 2$ & - & KM106324 & - \\
\hline Lophodermium australe & CMW 34720 & KF636499 & - & - \\
\hline Lophodermium australe & DP_SL1_1C & - & KM106346 & - \\
\hline Lophodermium baculiferum & loba2 Oregon & AY100658 & - & - \\
\hline Lophodermium baculiferum & mon2zem Nuevo Leon & AY100656 & - & - \\
\hline Lophodermium baculiferum & monbacp Morelos & AY100657 & - & - \\
\hline Lophodermium cathayae & HOU827 & - & KX443648 & - \\
\hline Lophodermium cathayae & HOU837 & HQ992810 & & \\
\hline Lophodermium cathayae & Hou837M & HQ992811 & & \\
\hline Lophodermium conigenum & $\mathrm{Ab} 1$ & HM060648 & HM060669 & - \\
\hline Lophodermium conigenum & Ab2 & - & HM060670 & - \\
\hline Lophodermium conigenum & Ab3 & HM060650 & HM060671 & - \\
\hline Lophodermium conigenum & Ab4 & - & HM060672 & - \\
\hline Lophodermium conigenum & CMW 39040 & KF636501 & - & - \\
\hline Lophodermium conigenum & HOU1227D & KX443659 & KX443646 & - \\
\hline Lophodermium conigenum & R114 & FJ861974 & - & - \\
\hline Lophodermium conigenum & R117 & FJ861976 & - & - \\
\hline Lophodermium corconticum & CCF 4780 & HG939565 & - & - \\
\hline Lophodermium corconticum & CCF 4781 & - & HG965439 & - \\
\hline Lophodermium corconticum & CCF $4868^{\top}$ & LM654179 & LM654182 & - \\
\hline Lophodermium corconticum & L178 & - & HG965447 & - \\
\hline Lophodermium corconticum & L204 & - & HG965440 & - \\
\hline Lophodermium indianum & CMW 39036 & KF636505 & - & - \\
\hline Lophodermium indianum & CMW 39038 & KF636507 & - & - \\
\hline Lophodermium indianum & CMW 39125 & KF636510 & - & - \\
\hline Lophodermium juniperinum & HOU1210 & KX443661 & - & - \\
\hline Lophodermium juniperinum & ICMP 17306 & KF033120 & - & - \\
\hline Lophodermium kumaunicum & HOU1112B & - & KX443651 & - \\
\hline Lophodermium kumaunicum & HOU514A & KX443660 & KX443649 & - \\
\hline Lophodermium kumaunicum & HOU812A & - & KX443650 & - \\
\hline Lophodermium macci & S-171 & AF540560 & - & - \\
\hline Lophodermium macci & S-172 & AF540561 & - & - \\
\hline
\end{tabular}




\begin{tabular}{|c|c|c|c|c|}
\hline Lophodermium molitoris & CV1_3a & KM106803 & - & - \\
\hline Lophodermium molitoris & ICMP 14900 & AY247752 & - & - \\
\hline Lophodermium nitens & 102C27_CP & - & DQ342126 & - \\
\hline Lophodermium nitens & 19_CP & - & DQ342122 & - \\
\hline Lophodermium nitens & $41 a 3$ & - & DQ342124 & - \\
\hline Lophodermium nitens & DAOMC 250027 & KR494247 & - & - \\
\hline Lophodermium nitens & NB-283-2D & KY485136 & - & - \\
\hline Lophodermium petrakii & $\mathrm{R} 60$ & FJ861984 & - & - \\
\hline Lophodermium piceae & ZK53/08 & FR837918 & - & - \\
\hline Lophodermium pinastri & 6 & EU696766 & - & - \\
\hline Lophodermium pinastri & Aa1 & HM060657 & HM060673 & - \\
\hline Lophodermium pinastri & Aa12 & - & HM060681 & - \\
\hline Lophodermium pinastri & Aa13 & HM060659 & HM060677 & - \\
\hline Lophodermium pinastri & Aa2 & - & HM060682 & - \\
\hline Lophodermium pinastri & Aa23 & - & HM060678 & - \\
\hline Lophodermium pinastri & Aa28 & - & HM060674 & - \\
\hline Lophodermium pinastri & Aa29 & - & HM060675 & - \\
\hline Lophodermium pinastri & $\mathrm{Aa} 4$ & - & HM060679 & - \\
\hline Lophodermium pinastri & Aa6 & HM060661 & HM060680 & - \\
\hline Lophodermium pinastri & Aa7 & - & HM060683 & - \\
\hline Lophodermium pinastri & Aa8 & HM060655 & HM060676 & - \\
\hline Lophodermium pinastri & Aa9 & - & HM060684 & - \\
\hline Lophodermium pinastri & HOU1227C & KX443658 & KX443645 & - \\
\hline Lophodermium pinastri & L230 & AY100650 & - & - \\
\hline Lophodermium pinastri & L23pinLo & AY775698 & - & - \\
\hline Lophodermium pinastri & L24pinLo & AY775699 & - & - \\
\hline Lophodermium pinastri & loppon & AY100649 & - & - \\
\hline Lophodermium pinastri & LUBC & AF462434 & - & - \\
\hline Lophodermium pinastri & R109 & FJ861985 & - & - \\
\hline Lophodermium pinastri & $\mathrm{R} 110$ & FJ861986 & - & - \\
\hline Lophodermium pinastri & Yinggao & AY422490 & - & - \\
\hline Lophodermium pini-bungeanae & $\mathrm{R} 112$ & FJ861989 & - & - \\
\hline Lophodermium pini-excelsae & R108 & FJ861988 & - & - \\
\hline Lophodermium pini-excelsae & R85 & FJ861987 & - & - \\
\hline Lophodermium pini-taiwanensis & HOU1073AM & & KX443640 & - \\
\hline Lophodermium pini-taiwanensis & HOU1073A ${ }^{\top}$ & KX443654 & KX443641 & - \\
\hline Lophodermium pini-taiwanensis & HOU1075B & - & KX443642 & - \\
\hline Lophodermium pini-taiwanensis & HOU1222B & - & KX443643 & - \\
\hline Lophodermium pini-taiwanensis & HOU1227B & - & KX443644 & - \\
\hline Lophodermium resinosum & DAOMC $251482^{\top}$ & KY485127 & KY485130 & KY485133 \\
\hline Lophodermium resinosum & DAOMC 251484 & KY485128 & KY485131 & KY485134 \\
\hline Lophodermium resinosum & DAOMC 251485 & KY485129 & KY485132 & KY485135 \\
\hline
\end{tabular}




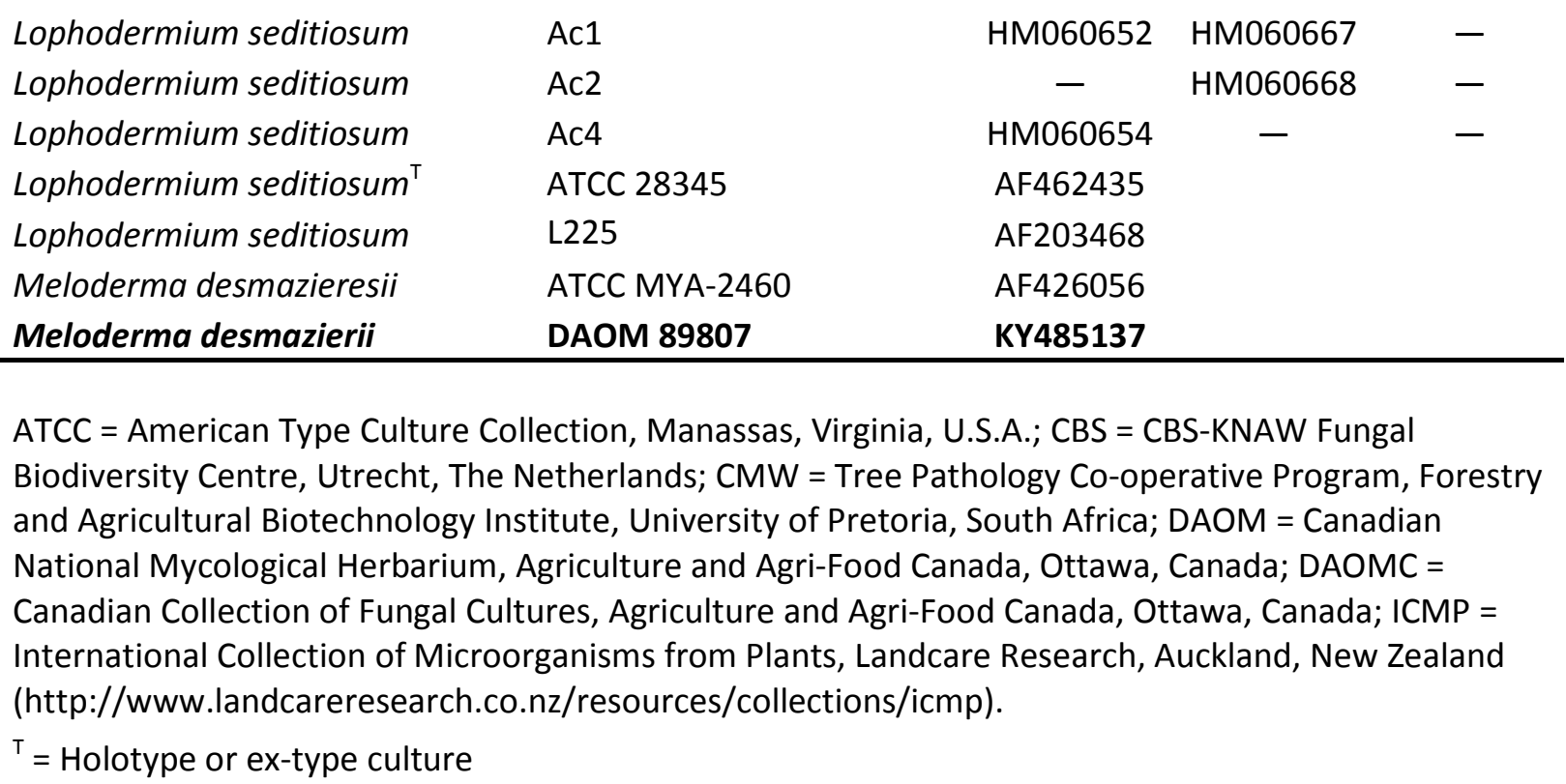




\section{Figure captions}

Fig. 1. Bayesian $50 \%$ majority rule consensus tree based on ITS dataset containing representative Lophodermium species and related genera. GenBank accession numbers precede the species name followed by culture collection accession numbers, with ex-type strains in bold. Branch Bayesian posterior probability values below 1.0 are presented at the nodes. The tree was rooted to Lophodermium piceae and the scale bar indicates the number of substitutions per site.

Fig. 2. Bayesian $50 \%$ majority rule consensus tree based on ACT dataset containing representative Lophodermium species and related genera. GenBank accession numbers precede the species name followed by culture collection accession numbers, with ex-type strains in bold. Branch Bayesian posterior probability values below 1.0 are presented at the nodes. The tree was rooted to Hymenoscyphus epiphyllus and the scale bar indicates the number of substitutions per site.

Fig. 3. Lophodermium resinosum morphology. (A-G) Symptomatic Pinus resinosa needles showing ascomata and conidiomata (arrows denoting conidiomata). (H) Vertical section showing subepidermal position of mature ascoma. (I) Basal and covering stroma of ascoma. (J, M) Covering stroma of ascoma underneath host epidermis. (K) Basal stroma, subhymenium, and hymenium of ascoma. (L) Close-up of ascoma lip cells embedded in mucous. (N) Asci and paraphyses mounted in $\mathrm{KOH}$. (O) Subepidermal conidiomata. (P) Conidiomata and conidia with covering host epidermis torn free. (Q) Gelatinous sheathes of ascospores evident within asci mounted in water. (R) Discharged ascospores mounted in water. (S) Conidia. (T) Conidiogenous cells. Scale bars: H, O-P = $100 \mu \mathrm{m}$; I-N, Q-T = $10 \mu \mathrm{m}$. 


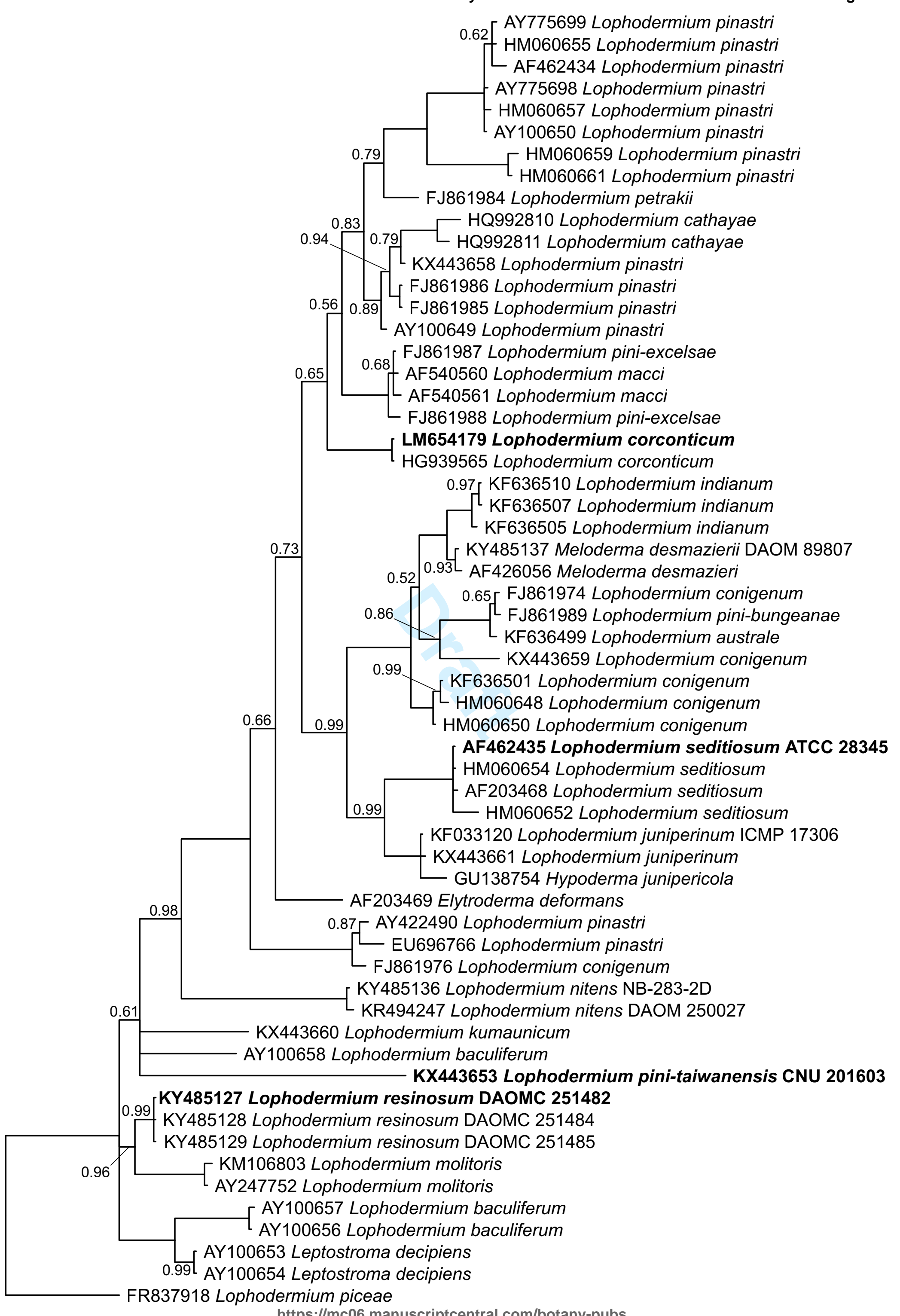

AY775699 Lophodermium pinastri

AF462434 Lophodermium pinastri

AY100650 Lophodermium pinastri

HM060659 Lophodermium pinastri

Lophodermium petrakii

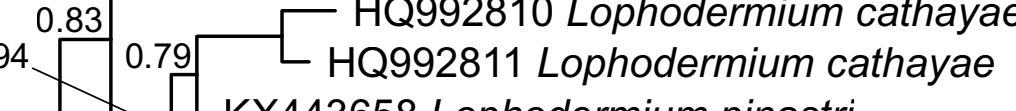

56 FJ861986 Lophodermium pinastri

FJ861987 Lophodermium pini-excelsae

AF540561 Lophodermium macci

J861988 Lophodermium pini-ex

LM654179 Lophodermium corconticum

0.97 KF636510 Lophodermium indianum

KF636507 Lophodermium indianum

KF636505 Lophodermium indianum

AF426056 Meloderma desmazieri

FJ861989 Lophodermium pini-bungeanae

KF636499 Lophodermium australe

KX443659 Lophodermium conigenum

KF636501 Lophodermium conigenum HM060654 Lophodermium seditiosum

AF203468 Lophodermium seditiosum

HM060652 Lophodermium seditiosum

KF033120 Lophodermium juniperinum ICMP 17306

KX443661 Lophodermium juniperinum

GU138754 Hypoderma junipericola

AF203469 Elytroderma deformans

87 AY422490 Lophodermium pinastri

— EU696766 Lophodermium pinastri

FJ861976 Lophodermium conigenum

KY485136 Lophodermium nitens NB-283-2D

KR494247 Lophodermium nitens DAOM 250027

KX443660 Lophodermium kumaunicum 


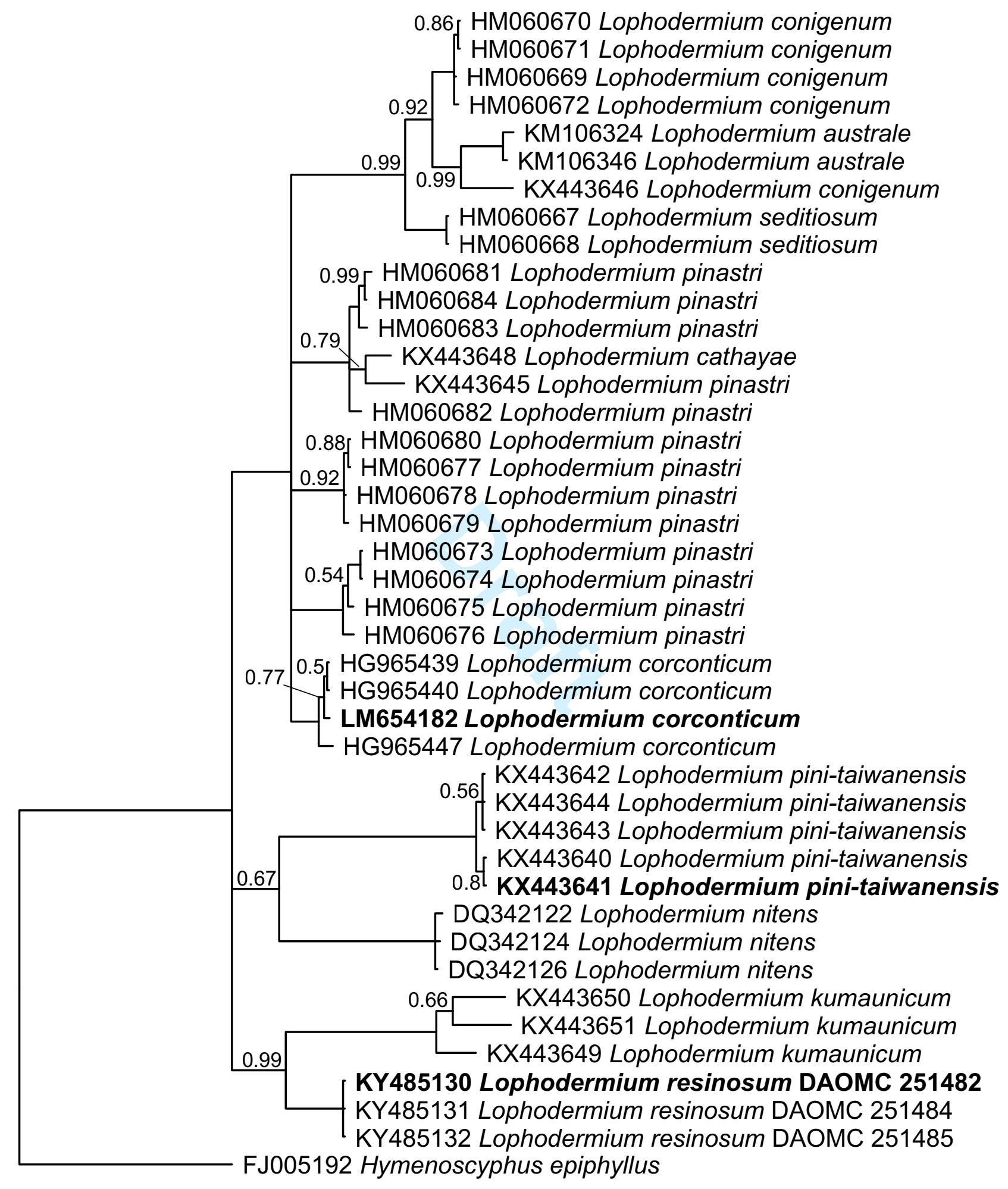

0.07 

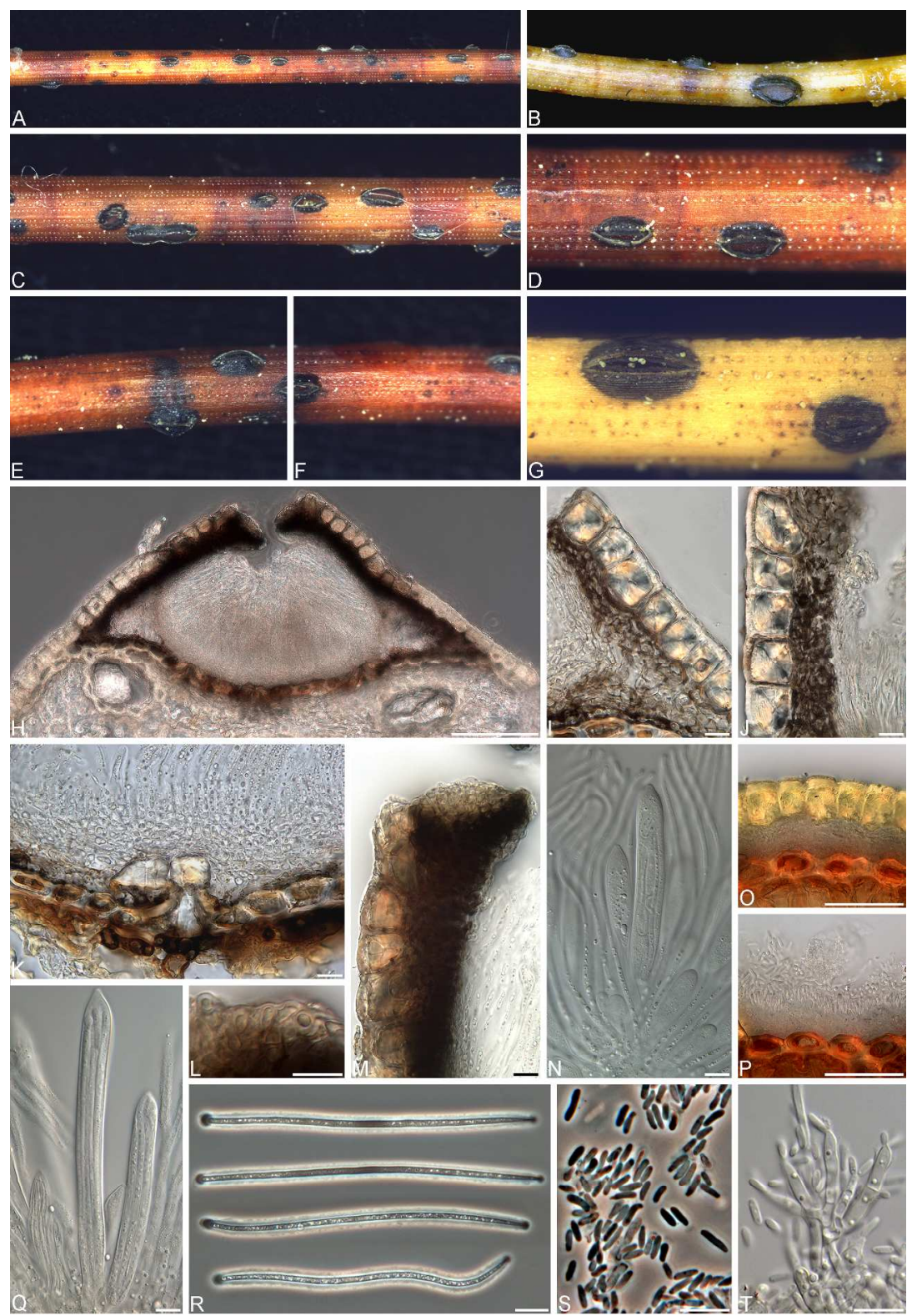

Lophodermium resinosum morphology. (A-G) Symptomatic Pinus resinosa needles showing ascomata and conidiomata (arrows denoting conidiomata). (H) Vertical section showing subepidermal position of mature ascoma. (I) Basal and covering stroma of ascoma. (J, M) Covering stroma of ascoma underneath host epidermis. (K) Basal stroma, subhymenium, and hymenium of ascoma. (L) Close-up of ascoma lip cells embedded in mucous. (N) Asci and paraphyses mounted in $\mathrm{KOH}$. (O) Subepidermal conidiomata. (P) Conidiomata and conidia with covering host epidermis torn free. (Q) Gelatinous sheathes of ascospores evident within asci mounted in water. (R) Discharged ascospores mounted in water. (S) Conidia. (T) Conidiogenous cells. Scale bars: $\mathrm{H}, \mathrm{O}-\mathrm{P}=100 \mu \mathrm{m} ; \mathrm{I}-\mathrm{N}, \mathrm{Q}-\mathrm{T}=10 \mu \mathrm{m}$.

Fig. 3

$180 \times 261 \mathrm{~mm}(300 \times 300 \mathrm{DPI})$ 